\title{
Explorando Resultados por Questão no Enade em Ciência da Computação para Subsidiar Revisão de Projeto Pedagógico de Curso
}

\author{
Andrea S. Charão ${ }^{1}$, Karina Wiechork ${ }^{1,2}$ \\ Marlon L. S. Rodrigues ${ }^{1}$, Fernando P. Barbosa ${ }^{1}$ \\ ${ }^{1}$ Universidade Federal de Santa Maria \\ Santa Maria, RS \\ ${ }^{2}$ Instituto Federal Farroupilha \\ Frederico Westphalen, RS \\ andrea@inf.ufsm.br, karinawiechork@gmail.com \\ mlrodrigues@inf.ufsm.br, fernando.pires.barbosalgmail.com
}

\begin{abstract}
Resumo. Este artigo relata uma experiência de exploração de resultados detalhados por questão, em provas do Enade de um curso de Bacharelado em Ciência da Computação, com o objetivo de reunir contribuições para a revisão de seu Projeto Pedagógico. A partir de relatórios do INEP para todas as cinco provas realizadas, obtiveram-se indicadores de possíveis fraquezas e forças do curso, analisando-se percentuais de acertos, conteúdos curriculares e enunciados das questões. Os dados estão disponibilizados online, podendo ser utilizados, com poucas substituições, por outras instituições avaliadas pelos mesmos exames.
\end{abstract}

\begin{abstract}
This article reports an experience of exploring detailed results per question, in Enade tests applied to students of a Bachelor of Computer Science course. The goal of this study was to gather contributions for the revision of the course's Pedagogical Project. From reports published by INEP for all five exams of the area, we sought indicators of possible weaknesses and strengths of the course, analyzing percentages of correct answers, topics and full contents of the questions. The data we collected are available online, so they can be used, with few substitutions, by other institutions evaluated by the same exams.
\end{abstract}

\section{Introdução}

O Exame Nacional de Desempenho dos Estudantes (Enade) é um componente importante da avaliação da qualidade do ensino superior brasileiro [INEP 2019a]. Aplicado desde 2004, pelo Instituto Nacional de Estudos e Pesquisas Educacionais Anísio Teixeira (INEP), o Enade compreende uma prova com questões discursivas e de múltipla escolha, divididas entre partes de formação geral e específica. O ciclo avaliativo é de três anos, sendo que a cada ano aplica-se a prova aos concluintes dos cursos de determinadas áreas de avaliação.

Os resultados do Enade são disponibilizados às instituições e ao público no ano seguinte à realização do exame. No site do INEP, encontra-se o histórico completo de provas, gabaritos e padrões de resposta, juntamente com relatórios de áreas e de cursos, todos disponibilizados em arquivos no formato PDF. São também disponibilizados os 
chamados "microdados", que são dados tabulares para importação em software de análise (R, Excel, etc.). Os arquivos disponibilizados são complementares, sendo que alguns dados e informações só se encontram nos PDFs ou nos microdados.

Muitos trabalhos de pesquisa têm se dedicado a analisar resultados do Enade, principalmente usando os microdados. Para equipes responsáveis por revisar e reformular Projetos Pedagógicos de Cursos, os dados do INEP e os resultados de análises/pesquisas servem como um importante referencial. Na Universidade Federal de Santa Maria, visando subsidiar a reformulação do Projeto Pedagógico de Curso (PPC) do Bacharelado em Ciência da Computação, exploramos os dados do INEP sob uma ótica que ainda não havia sido considerada, abrangendo resultados questão por questão para todas as cinco edições do exame, buscando assim indícios de possíveis fraquezas e forças do curso. No restante deste artigo, discutem-se brevemente alguns trabalhos relacionados (Seção 2), para depois detalhar-se a experiência (Seção 3), que incluiu a extração de dados de documentos em PDF. Ao final (Seção 4), destacam-se as lições aprendidas e indicam-se as URLs para obtenção dos dados coletados, que podem ser úteis a outras instituições.

\section{Trabalhos Relacionados}

Na literatura, encontram-se diversos trabalhos que extraem conclusões a partir de resultados do Enade, com diferentes objetivos e abordagens de análise [Lima et al. 2019]. O próprio INEP, a cada edição, apresenta estatísticas e observações detalhadas por áreas, em seus Relatórios Síntese, e também para cada curso avaliado, nos Relatórios de Curso [INEP 2019b].

Algumas análises têm foco amplo (ensino superior), enquanto outras se concentram em uma área ou curso. Na área de Computação, alguns autores têm explorado resultados do Enade, tanto de suas provas como dos questionários que também o compõem, para identificar aspectos que merecem atenção. Por exemplo, Landes e Manhães [2018] analisaram atributos dos participantes (sexo e idade) e suas notas para quatro edições do Enade, a partir dos microdados. Entre os resultados, os autores chamam atenção para médias baixas, abaixo de 5, para componentes de formação específica. No trabalho de Lima et al. [2018], também foram analisados os microdados de quatro edições do exame, porém com foco no desempenho por questão, considerando um agrupamento das questões por conteúdos de referência, conforme definido pela comissão assessora da área no INEP. Os resultados colocam em evidência, por exemplo, um grande quantitativo de notas zero em questões discursivas, além de conteúdos que aparecem com maior ou menor frequência nas provas.

Análises de resultados gerais por área são inegavelmente importantes para avaliar e buscar a melhoria da qualidade do ensino superior brasileiro [Griboski 2012]. Porém, em um contexto mais focado, buscando a melhoria de um curso específico em uma instituição, não encontraram-se trabalhos que reportem a exploração de dados do Enade questão por questão, como subsídio para identificar fraquezas e forças de um curso de Ciência da Computação. É neste nicho pouco explorado que se insere o presente trabalho.

\section{Descrição da Experiência}

A motivação para este trabalho surgiu no âmbito do Núcleo Docente Estruturante (NDE) do curso de Bacharelado em Ciência da Computação da Universidade Federal de Santa Maria. O trabalho foi organizado como um estudo exploratório abrangendo todos os exames realizados pelos concluintes do curso. 


\subsection{Objetivos e Questão de Pesquisa}

O principal objetivo do estudo foi reunir contribuições para apoiar a revisão do PPC, a partir de relatórios publicados pelo INEP, de modo a responder a seguinte questão de pesquisa: Em quais conteúdos curriculares do Enade os alunos de Ciência da Computação da UFSM têm apresentado histórico de desempenho abaixo ou acima do nacional? Definiu-se esta questão para complementar discussões do NDE sobre dados locais de desempenho de alunos em disciplinas, entendendo-se que essa discussão poderia ser ampliada considerando os resultados do Enade, que é o instrumento nacional de avaliação dos cursos. Mais do que isso, supôs-se que uma comparação com o desempenho nacional poderia trazer observações valiosas que não se encontram nos dados locais, da UFSM.

\subsection{Coleta e Preparação dos Dados}

Diferentemente de outros trabalhos relacionados que utilizaram microdados, este estudo utilizou documentos do INEP publicados em formato PDF: provas, relatórios síntese de área e relatórios de curso. Optou-se por esta abordagem porque os microdados não contêm, por exemplo, o enunciado das questões e sua classificação por conteúdos curriculares. Além disso, nos relatórios de curso encontram-se consolidados os percentuais de acertos por questão, tanto pelos alunos do curso como pelos demais alunos de todo o Brasil.

Os documentos foram processados para obtenção dos seguintes atributos de cada questão: ano da prova, parte da prova (formação geral ou específica), tipo de questão (múltipla escolha ou discursiva), identificador da questão, imagem com enunciado da questão, gabarito, conteúdos curriculares abordados, percentual de acertos do curso, percentual de acertos no Brasil e a diferença entre percentuais de acerto no curso e no Brasil.

A extração dos dados contidos nos arquivos em PDF foi feita de forma semiautomatizada, utilizando o software Tabula ${ }^{1}$, que extrai dados tabulares de PDFs, e também um software em desenvolvimento na UFSM, que identifica regiões e extrai recortes de arquivos PDF. Após as extrações realizadas com auxílio de ferramentas, procedeu-se à conferência manual dos dados extraídos. Ao todo, reuniram-se dados sobre as 200 questões das provas do Enade realizadas pelos concluintes de Ciência da Computação da UFSM.

\subsection{Classificação das Questões por Conteúdos Curriculares}

Para realizar análises sobre um histórico de provas, é necessário adotar uma classificação comum para os conteúdos curriculares abordados nas questões. Tais conteúdos são baseados nas diretrizes curriculares nacionais para os cursos de graduação, mas a cada edição estes são agrupados de forma diferente pelas comissões assessoras do INEP. Assim, nas cinco edições do exame de Ciência da Computação, houve variação no agrupamento dos conteúdos de formação específica: 15 tópicos em 2005 e 2008, 21 em 2011 e 17 em 2014 e 2017. Exemplos de tópicos são "Banco de Dados" ou "Sistemas Distribuídos", que podem se relacionar a uma ou mais disciplinas nos cursos. Os tópicos de formação geral são ainda mais variáveis. Nos exames de 2014 e 2017, os relatórios síntese de área enquadram cada questão em até três tópicos, dentre os conteúdos curriculares previstos. Nas edições anteriores, o relatório síntese apenas lista os conteúdos, sem classificar cada questão.

A escolha de uma classificação de referência não foi uma decisão trivial neste estudo, pois diferentes agrupamentos poderiam levar a diferentes resultados sobre fraquezas

\footnotetext{
${ }^{1}$ Disponível em: https://tabula.technology/
} 
ou forças do curso. Adotar uma classificação por disciplinas poderia nos distanciar do enquadramento feito pelo INEP em 2014 e 2017, por isso tomou-se por referência as 17 categorias de conteúdos de formação específica do último exame (2017). Comparando-se esta classificação com a de 2014, que também se baseou em 17 categorias, encontraram-se poucas diferenças e com isso se pôde facilmente reclassificar as questões desta edição. Para os exames de 2005, 2008 e 2011, um especialista realizou manualmente a classificação de cada questão, tomando por base seu enunciado e as 17 categorias de conteúdos, atribuindo até três tópicos por questão. As questões de formação geral foram agrupadas em uma única categoria e, por limitação de espaço, não são consideradas neste artigo.

\subsection{Resultados e Discussão}

A fim de responder à questão de pesquisa, calculou-se, para cada um dos 17 tópicos de formação específica, o quantitativo de questões não anuladas e a média aritmética de diferenças de percentuais de acertos do curso e do Brasil. Os resultados encontram-se na Tabela 1, ordenados em ordem crescente das médias calculadas. Para questões de Probabilidade e Estatística, a média é negativa, de $-8,8$ pontos percentuais, considerando 3 questões. Esse resultado foi um tanto surpreendente, pois, em discussões do NDE sobre dados locais de desempenho em disciplinas, esta área não foi considerada problemática.

Para muitos conteúdos, observa-se um desempenho histórico significativamente maior que o nacional, acima de 10 pontos percentuais, o que pode indicar forças do curso, ou seja, áreas em que a qualidade da formação oferecida pelo curso está mais fortalecida, considerando o contexto brasileiro. Alguns desses conteúdos se relacionam a disciplinas com alta taxa de reprovação, que tendem a ser alvo de mudanças em reformas curriculares, portanto resta o desafio de equilibrar indicadores locais e nacionais. Observam-se também conteúdos cujo percentual de acertos está pouco acima do nacional, o que indica áreas em que o curso exige um olhar mais atento do NDE.

\section{Considerações Finais}

Este trabalho explorou resultados do Enade para subsidiar a busca por melhorias em um curso de Ciência da Computação. A experiência reuniu dados e revelou informações que não estavam evidentes nos relatórios do INEP, podendo a partir de agora embasar outros estudos e discussões. O uso ou não deste tipo de informação cabe a cada NDE, que deve refletir sobre os diferentes indicadores disponíveis. Uma importante lição aprendida com esta experiência é que a classificação de questões por conteúdos representa um desafio e uma possível ameaça à validade deste tipo de estudo, uma vez que há muitas possibilidades de agrupamento dos conteúdos. Refazer as análises com diferentes classificações pode ser uma solução, juntamente com a revisão dos enunciados e classificações por múltiplos especialistas. Visando favorecer a replicação da experiência em outros cursos da área, os dados foram organizados em planilhas no Google Spreadsheets, compartilhadas em modo público $^{2}$. Também desenvolveu-se uma interface web $^{3}$ para apresentação dos dados, com controles interativos para busca/filtragem, ordenação dos dados e visualização de imagem de cada questão, como alternativa para facilitar a exploração dos dados por especialistas.

\footnotetext{
${ }^{2}$ Disponível em: http://bit. Iy/enadeccufsmwei2020

${ }^{3}$ Disponível em: http: / / andreainfufsm.github. io/enadeccufsmwei2 020
} 


\begin{tabular}{l|r|r}
\hline Conteúdo Curricular & $\begin{array}{r}\text { Média de } \\
\text { Diferenças } \\
\text { Curso-Brasil }\end{array}$ & $\begin{array}{r}\text { Qtde. de } \\
\text { Questões }\end{array}$ \\
\hline Probabilidade e Estatística & $-8,8$ & 3 \\
Engenharia de Software e Interação Homem-Computador & 3,7 & 12 \\
Redes de computadores & 6,1 & 11 \\
Teoria da Computação & 8,3 & 12 \\
Banco de Dados & 9,0 & 8 \\
Inteligência Artificial e Computacional & 10,4 & 5 \\
Lógica e Matemática Discreta & 11,7 & 14 \\
Teoria dos Grafos & 12,6 & 6 \\
Computação Gráfica e Processamento de Imagem & 14,0 & 5 \\
Ética, Computador e Sociedade & 15,9 & 4 \\
Fundamentos e Técnicas de Programação & 16,1 & 12 \\
Arquitetura de Computadores e Sistemas Operacionais & 17,1 & 13 \\
Paradigmas de Linguagens de Programação & 18,6 & 6 \\
Algoritmos e Estruturas de Dados & 18,8 & 23 \\
Sistemas Digitais & 22,1 & 6 \\
Sistemas Distribuídos & 23,6 & 2 \\
Compiladores & 24,8 & 10 \\
\hline
\end{tabular}

Tabela 1. Diferenças entre percentuais de acertos (Curso-Brasil) por tópicos de formação específica, 2005-2017 (médias expressas em pontos percentuais)

\section{Referências}

Griboski, C. M. (2012). O Enade como indutor da qualidade da educação superior. Estudos em Avaliação Educacional, 23(53).

INEP (2019a). Exame nacional de desempenho dos estudantes (Enade). Disponível em: http://portal.inep.gov.br/enade Acesso em: 10 de março de 2020.

INEP (2019b). Resultados Enade. Disponível em: http://portal.inep.gov.br/web/guest/relatorios Acesso em: 10 de março de 2020.

Landes, F. B. e Manhães, L. M. B. (2018). Análise dos exames do ENADE para os cursos de computação utilizando o software R. Revista do Seminário Internacional de Estatística com R, 3(1):1 - 14 .

Lima, P. d. S. N., Ambrósio, A. P., Félix, I. M., e Brancher, J. D. (2018). SysEnade análise das questões de provas do Enade organizadas pelos temas abordados. In Anais dos Workshops do VII Congresso Brasileiro de Informática na Educação (WCBIE 2018), pages $419-428$.

Lima, P. d. S. N., Ambrósio, A. P. L., Ferreira, D. J., e Brancher, J. D. (2019). Análise de dados do Enade e Enem: uma revisão sistemática da literatura. Avaliação: Revista da Avaliação da Educação Superior (Campinas), 24:89 - 107. 